advanced sandwich courses, the director, Mr. Leslie Farrer-Brown, has indicated that the Foundation would be prepared to consider any requests for financial help which would lead to improvement in the quality of technological education provided by the colleges. The Foundation in no way seeks to limit the way in which senior colleges of technology will develop and hopes that each will grow in a manner in which it can best serve the needs of industry. As education for technology must be given parity in technical institutions and in industry, there is room for considerable experiment about the ways in which this should be organized. So, too, with the teaching methods which have yet to be evolved. Among a number of tentative proposals, FarrerBrown indicates that "perhaps, in suitable cases, the attainment and maintenance of high standards of teaching and the complementary training in industry, might be fostered if teachers of their colleges and their associated educational staffs in industry had the opportunity to study educational mothods at technological institutions overseas". In the first place principals have been invited to submit informal proposals.

\section{Leverhulme Trust}

THE second report of the Leverhulme Trustees classifies the awards made during the first twenty-five years of the activities of the Leverhulme Trust Fund (The Leverhulme Trust. Analysis of Grants 19321955 : Second Report. Pp. 18. London: The Leverhulme Trust, 1959). Of the total of $£ 854,358$, $£ 179,400$ was awarded to universities and centres of higher education; $£ 84,000$ to learned societies,

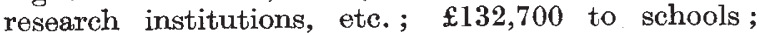
$£ 3,600$ to archæology; $£ 54,000$ to the arts; $£ 28,300$ to architecture and town planning; $£ 115,300$ to

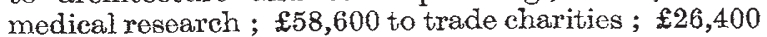
to trade educational grants ; $£ 40,800$ to miscellaneous grants, with $£ 131,258$ on the Advisory Committee, individual research awards and grants. No capital grants or contributions are made to appeals of a general nature. Long-term grants are, as a rule, excluded, and broadly speaking the Fund goes mainly to the furtherance of research in the universities, teaching hospitals and other centres of higher education, the Trustees' primary concern being to foster new ideas which may lack support from other sources.

\section{Scientific Research in Schools}

THE Committee on Scientific Research in Schools which was established by the Council of the Royal Society on March 7, 1957, reports that interest shown by schools in undertaking research projects has increased and all the research projects originally supported by Shell Research, Ltd., have now been transferred to the Committee. There are now forty-eight schools undertaking scientific research; some of the schools have more than one project under way and a total of fifty-seven separate research projects are now being administered compared with twenty-five projects last year. Various requests for advice have also been received from another two schools and these are under consideration. During the year a sum of more than $£ 2,000$ has been granted to those carrying out research. The Council of the Royal Society has provided a sum of $£ 2,000$ and Shell Research, Ltd., have given an additional $£ 12710 \mathrm{~s}$. in addition to their support of research in two schools. A schemo has also been arranged with the Director of the National Physical Laboratory, whereby, during the summer holidays, schoolmasters selected by the Science Masters' Association can visit the Laboratory and carry out some scientific work there. All research projects with which the Committee is dealing are carried out with the specialist advice and assistance of Fellows of the Royal Society and by others who have agreed to act as advisers. The Committee has been stimulated by the continued and growing response to its scheme and looks forward both to receiving further requests from schoolmasters and schoolmistresses and to the continued support of the Fellows of the Royal Society and others in acting as advisers and assistants in the extension of its activities. This enterprising scheme should do much to raise the standard of science teaching in schools.

\section{The Geological Survey of Great Britain}

The Summary of Progress of the Geological Survey and Museum for 1958 records much work in the field and offices. With regret, however, it directs attention to the shortage of trained cartographical draughtsmen, who are so important in the preparation of the publication of geological maps. This regret is indeed shared by many who have to wait for such long periods to see the results of the field and subsequent reports that have been prepared by the geologists. Primary survey has been carried out in several areas and revision was continued mainly in areas of economic importance, particularly the coalfields. Statistics of mapping are given for the quinquennium. Exploratory boring is now an important part of the work of the Survey and the results of various geophysical methods are interesting. The Survey has continued as geological consultant to the United Kingdom Atomic Energy Authority, and an airborne radiometric survey of the remainder of Cornwall, much of Devon and part of Somerset has been undertaken. The Museum attracted nearly 390,000 visitors, and re-organization of the reserve mineral and economic collections and research upon them continued.

\section{A Technique for Capturing Birds and Mammals}

Capturing large numbers of wild birds and mammals for the purpose of marking the animals for ecological and behavioural studies is usually a difficult task. A paper by Ronald F. Labisky describes a technique which was found effective for capturing pheasants (Phasianus colchicus) and certain other animals by using bright lights at night to blind them temporarily ("Biological Notes", No. 40. Natural History Survey Division, University of Illinois). The capturing of pheasants by night-lighting, also called 'jack-lighting' or 'shining', has been employed in practical game management since the late 1920's. Oscar Johnson reported that workers in South Dakota captured about 10,000 pheasants during the winter of 1926-27, and 12,000 pheasants during the winter of 1929-30, by 'shining' roosting birds with motor-car headlights. More recently, workers in Idaho, South Dakota, Nebraska and California have employed night-lighting in capturing pheasants. In Illinois, one of the problems in pheasant research has been that of capturing and marking a large enough number of wild pheasants to permit investigations of behaviour, population dynamics and movements. While bait trapping of wild pheasants is successful in many States, it is difficult, or frequently impossible, in east-central Illinois during autumn and winter; this difficulty is probably the result of an abundant. year-round food supply and moderate winter weather. 